\title{
Enfermedad de Rendu Osler Weber: presentación de un caso
}

Rendu Osler Weber Disease: a case report

\author{
Ana Arévalo Gómez, Susana Rivera García, Oscar Porto Fuentes, Fernando de la Iglesia Martínez \\ Unidad de Enfermedades Minoritarias. Servicio de Medicina Interna. Complejo Hospitalario Universitario A Coruña
}

\section{RESUMEN}

La Telangiectasia Hemorrágica Hereditaria o Enfermedad de Rendu-OslerWeber, es una entidad infradiagnosticada y el retraso diagnóstico es frecuente, lo que va a dificultar el screening y tratamiento preventivo de los pacientes y de sus familiares afectos. Presentamos el caso de una paciente que debutó con una complicación grave de la enfermedad, a pesar de lo cual el diagnóstico de la enfermedad no se realizó hasta pasados 10 años.

Palabras clave: Síndrome de Rendu Osler Weber, malformaciones arterio-venosas, telangiectasia hemorrágica hereditaria; epistaxis.

\section{INTRODUCCIÓN}

La Telangiectasia Hemorrágica Hereditaria (THH) o Enfermedad de Rendu-Osler-Weber es una enfermedad minoritaria de herencia autosómica dominante caracterizada por epistaxis espontáneas y recurrentes, telangiectasias múltiples mucocutáneas en sitios característicos y en ocasiones telangiectasias gastrointestinales y malformaciones arteriovenosas (MAV) pulmonares, hepáticas, cerebrales y/o espinales ${ }^{1-3}$. Conlleva una morbimortalidad importante y puede asociar complicaciones graves algunas de las cuales pueden ser prevenibles con un diagnóstico precoz y un seguimiento multidisciplinar adecuado, del que no siempre disponen. Presentamos el caso de una paciente que debutó con una complicación grave de la enfermedad, a pesar de lo cual el diagnóstico de la enfermedad no se realizó hasta pasados 10 años.

\section{CASO CLÍNICO}

Mujer de 54 años que ingresa en 2004 por cefalea y vómitos. Refería epistaxis frecuentes desde la infancia y migrañas desde los 20 años que trataba con Hemicranealß. No refería otros antecedentes médico quirúrgicos de interés, ni alergias ni hábitos tóxicos, ni recibía otros tratamientos.

Relataba cuadro de aproximadamente 15 días de evolución de cefalea holocraneal progresiva diferente a su migraña habitual, con escasa respuesta a analgésicos y que aumentaba en intensidad con maniobras vagales. Asociaba visión borrosa progresiva y el día del ingreso vómitos sin fiebre, dolor abdominal ni vómitos. Negaba rinorrea, otalgia u otorrea. No refería síndrome general ni otra sintomatología por aparatos.

A la exploración física presentaba un buen estado general, presión arterial de 130/70 mmHg y Ta $^{\mathrm{m}}$ de $37^{\circ} \mathrm{C}$. La auscultación cardiopulmonar y la exploración de cabeza y cuello, otorrinolaringológica (ORL) y abdominal eran normales así como la exploración neurológica. No se palpaban adenopatías a ningún nivel ni nódulos mamarios.

\begin{abstract}
Hereditary heamorrhagic telangiectasia or Rendu Osler disease is an underdiagnosed condition with long diagnostic delay time which will make difficult the screening and early treatment of patients and affected family members. We report a case of a patient diagnosed 10 years lapsing from initial onset of severe complications of the disease.
\end{abstract}

Keywords: Osler Weber Rendu syndrome, arteriovenous malformations, hereditary hemorrhagic telangiectasia, epistaxis.

En los estudios complementarios realizados inicialmente destacaba una leve leucocitosis de $13200 \times 106 / \mathrm{L}$ con $72 \%$ de polimorfonucleares y ferropenia con sangre oculta en heces negativa, siendo el resto de parámetros analíticos (incluído función renal, hepática e iones) normales. La velocidad de sedimentación globular era de $20 \mathrm{~mm}$. Los hemocultivos y la serología de VIH fueron negativos

En la radiografía de tórax se apreciaba una imagen de aspecto nodular en hemitórax izquierdo y en el TC craneal una lesión occípito-cortical derecha con significativo edema perilesional (Imagen 1).

Con sospecha de enfermedad tumoral metastásica de probable origen pulmonar se solicitó una tomografía (TC) toracoabdominal en la que se apreciaron imágenes nodulares suges-

Imagen 1. TC craneal con contraste. Lesión ocupante de espacio con efecto masa ubicada en la región occipito-cortical derecha. Se aprecia la lesión con centro hipodenso y bordes con realce en forma anular (flecha negra).

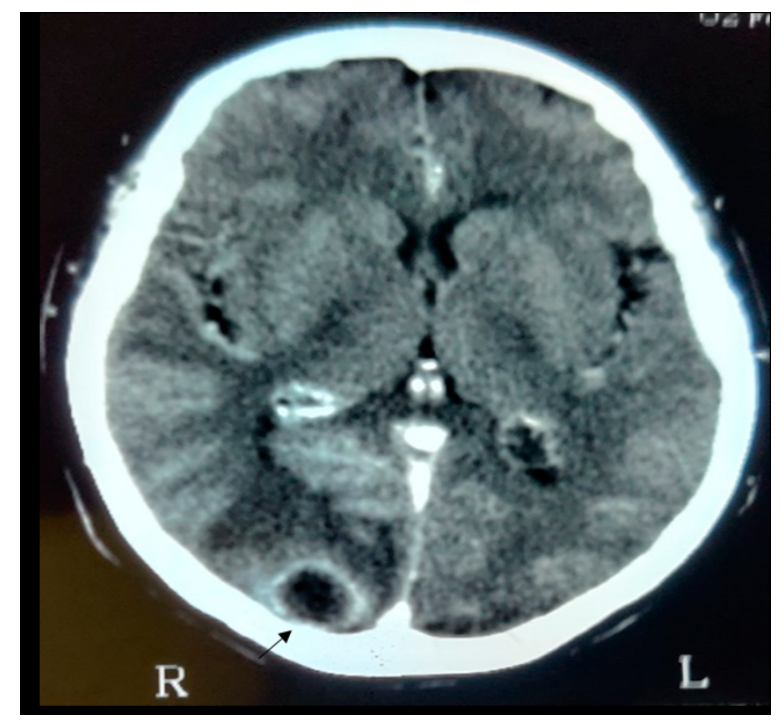


Imagen 2. TC torácico. Se aprecian imágenes nodulares sugestivas de fístulas arteriovenosas en LSI como único hallazgo (flecha blanca).

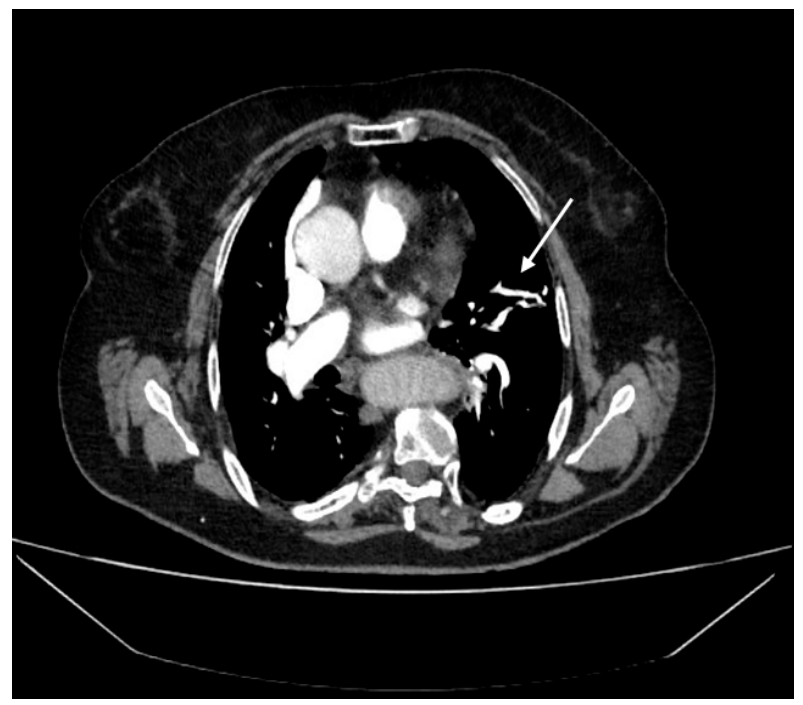

tivas de fístulas arteriovenosas en lóbulo superior izquierdo (LSI) como único hallazgo (Imagen 2), y una resonancia nuclear magnética (RM) cerebral que evidenciaba la lesión ya conocida en lóbulo occipital derecho a nivel corticosubcortical, sugestiva de absceso. A pesar de tratamiento antibiótico con ceftriaxona y metronidazol la lesión no se resolvió, siendo preciso drenaje quirúrgico obteniéndose material purulento (sin crecimiento microbiano tras antibioterapia prolongada). La evolución posterior fue favorable con resolución de la clínica y de la lesión cerebral.

La paciente rechazó la corrección de las malformaciones arterio-venosas (MAV) pulmonares y ocho años más tarde ingresó en Medicina Interna por infección respiratoria objetivándose anemia ferropénica. En la anamnesis dirigida relata epistaxis de repetición, sin otro foco de sangrado. En la exploración física se aprecian múltiples telangiectasias en piel a nivel de cara y tórax además de labios, lengua, paladar y pulpejos de dedos. Relata que su hijo y nieto presentan también epistaxis de repetición, por lo que se diagnostica de THH en base a los criterios de Curacao (epistaxis recurrentes espontáneas, telangiectasias cutáneo-mucosas, antecedentes familiares de primer grado afectos y MAV pulmonares).

Se remite a la consulta de enfermedades minoritarias para seguimiento. Precisó esclerosis con etoxiesclerol por persistencia de epistaxis recurrentes y anemización a pesar de medidas tópicas, con mejoría significativa de los sangrados y de la anemia. No presentó otras complicaciones.

Se realizó TC torácico de control que mostró una nueva MAV en lóbulo superior derecho (LSD) pero la paciente continua rechazando embolización. Se le indicó profilaxis antibiótica en caso de procedimientos que supusiesen riesgo de bacteriemia para minimizar el riesgo de un nuevo absceso, entre otras medidas. No se identificaron MAV hepáticas ni se describían a nivel del sistema nervioso central (SNC) en la RM cerebral realizada en 2004.

\section{DISCUSIÓN}

La THH es una enfermedad genética autosómica dominante con una prevalencia aproximada de 1/5000-1/80001-3. En el $97 \%$ de los pacientes se identifica una mutación en el gen ENG (THH tipo 1), en el genACVRL1 (THH tipo 2) 0 en el SMAD4 (síndrome de superposición con poliposis colónica juvenil) $)^{2,3}$. Dichos genes codifican proteínas de la pared celular cuyas alteraciones dan lugar a un crecimiento vascular anómalo. La afectación vascular se sitúa tanto a nivel de la microvasculatura en forma de telangiectasias en piel, mucosa nasal y gastrointestinal como en forma de malformaciones vasculares en vasos de mayor tamaño.

Aunque de penetrancia y expresividad variable, la mayoría de los pacientes presentan múltiples telangiectasias mucocutáneas de forma característica en lugares atípicos (labios, lengua, mucosa bucal y pulpejos de los dedos) que se desarrollan con la edad y que deben alertar de la posibilidad de la enfermedad ${ }^{2}$. Las epistaxis recurrentes están presentes en más del $90 \%$ de los casos y pueden comenzar en la infancia pudiendo dar lugar a anemia ferropénica y precisar tratamiento con hierro oral 0 iv 0 incluso trasfusiones sanguíneas periódicas (se recomienda a todos los adultos y niños realización de analítica con hemograma y ferrocinética) ${ }^{1}$. Suelen cursar en clusters y precipitarse por alcohol, picantes, o comidas ricas en salicilatos entre otros que se recomienda evitar, así como emplear tratamientos preventivos tópicos como la humidificación nasal y los sprays nasales salinos. Si fuese preciso puede emplearse acido tranexámico oral o considerar tratamientos ablativos como láser, ablación por radiofrecuencia, electrocirugía o escleroterapia (evitar la cauterización) $)^{1,2}$.También se emplean inyecciones submucosas intranasales de bevacizumab con resultados variables ${ }^{4}$. Si ello fracasa podrían considerarse tratamientos sistémicos como el tamoxifen $0^{5}$,agentes antiangiogénicos sistémicos como bevacizumab iv, o tratamientos como la talidomida ${ }^{6}$ 0 el raloxifeno ${ }^{7}$ (aunque con efectos secundarios adversos frecuentes y experiencia limitada). En casos extremos podría recurrirse a la septodermoplastia 0 cierre de narinas ${ }^{1,2}$.

Los sangrados digestivos secundarios a MAV (generalmente localizadas a nivel gastroduodenal) están presentes en cerca de $1 / 3$ de los pacientes y suelen aparecer a partir de los 40 años, precisando electrocoagulación endoscópica con argón. No es habitual un sangrado grave recurrente, pero pueden precisar tratamientos sistémicos ${ }^{1-2}$.

Algunos pacientes asocian MAV, generalmente múltiples, que pueden estar presentes en la infancia o la pubertad. Las más frecuentes se localizan a nivel pulmonar (50\%), la mayoría asintomáticas (ocasionalmente hipoxemia y policitemia) pero $1 / 3$ pueden tener cianosis 0 acropaquias. Las complicaciones derivadas de ellas pueden ser migrañas 0 accidentes cerebrovasculares por embolismos paradójicos y en un 6-8\% de los casos abscesos cerebrales por émbolos sépticos ${ }^{1-3,8-9}$. En todos los pacientes debe hacerse despistaje de las mismas, mediante ecocardiograma con contraste (en caso de sugerir 
un shunt extracardiaco debe confirmarse mediante TC con contraste). Estas MAV deben tratarse generalmente mediante embolización, en caso de ser sintomáticas, 0 en asintomáticas con un diámetro de la arteria nutricia $\geq 2 \mathrm{~mm}^{10}$ ya que ha demostrado reducir la morbimortalidad ${ }^{11}$. Debe aconsejarse evitar bucear, mantener una buena higiene dental y profilaxis antibiótica para procedimientos con riesgo de bacteriemia ${ }^{1-3}$. La THH puede cursar con hipertensión pulmonar bien por incremento del flujo pulmonar secundario a MAV y/o anemia 0 bien por Hipertensión arterial pulmonar primaria. El riesgo de tromboembolismo venoso está aumentado y no está contraindicado la profilaxis o tratamiento con anticoagulantes ${ }^{1-3}$.

La clínica y pronóstico de las MAV cerebrales (afectan a un $10 \%$ de los pacientes) dependen del tipo y localización de la lesión. Con frecuencia son múltiples y silentes. Dado que las MAV cerebrales asintomáticas no está demostrado que deban tratarse, asociando incluso su tratamiento un mayor riesgo de sangrado ${ }^{12}$, muchos países solo realizan screening de las mismas mediante RM con contraste en pacientes sintomáticos.

Las MAV hepáticas están presentes en $>2 / 3$ de los casos y generalmente son también asintomáticas (aunque pueden producir insuficiencia cardiaca por alto gasto cardiaco, hipertensión portal o isquemia biliar). Se aconseja su screening a todos los pacientes mediante ecografía doppler, TC o RM con contraste. En caso de complicaciones graves el tratamiento de elección es el trasplante hepático, y si este no es posible podría emplearse bevacizumab iv. Debe evitarse la embolización de las lesiones por el riesgo elevado de complicaciones ${ }^{1,13}$.

El diagnóstico de la enfermedad se realiza en base a los criterios de Curaçao (Tabla 1) aunque en la actualidad se aconseja la confirmación por estudio genético ${ }^{1-3}$.

Tabla1. Diagnóstico definido: $\geq 3$ criterios presentes, posible si 2 criterios e improbable si $<2$ criterios.

\begin{tabular}{|l|}
\hline Criterios de Curaçao \\
\hline Epistaxis: recurrente y espontánea \\
\hline $\begin{array}{l}\text { Telangiectasias múltiples en sitios característicos: labios, cavidad } \\
\text { oral, dedos, nariz }\end{array}$ \\
\hline $\begin{array}{l}\text { Lesiones viscerales comotelangiectasias gastrointestinales, MAV } \\
\text { pulmonares, hepáticas, cerebrales o espinales }\end{array}$ \\
\hline $\begin{array}{l}\text { Historia Familiar: } 1 \text { familiar de primer grado con THH según estos } \\
\text { criterios }\end{array}$ \\
\hline
\end{tabular}

A pesar de la historia de sangrados recurrentes desde la infancia con ferropenia secundaria y las telangiectasias de localización característica, el diagnóstico de la enfermedad en nuestra paciente pasó desapercibido incluso cuando debutó con un absceso cerebral en el contexto de una MAV pulmonar. El diagnóstico precoz podría haber evitado la complicación que presentó y que pudo ser fatal. Recibió cauterización de lesiones nasales en diversas ocasiones pero no fue hasta el diagnóstico que se le aplicó el tratamiento local adecuado que consiguió una mejoría de las epistaxis y de su calidad de vida. A raíz de su diagnóstico se confirmó la enfermedad en su hijo y nieto.

LA THH es una entidad infradiagnosticada y el retraso diagnóstico es frecuente, como se manifiesta en nuestro caso clínico, lo que va a dificultar el screening y tratamiento preventivo del paciente y de sus familiares afectos. Es por ello que un manejo y seguimiento adecuado de la enfermedad puede modificar su expectativa de vida ${ }^{3,14}$ pudiendo evitar complicaciones graves como la que presentó nuestra paciente.

\section{BIBLIOGRAFÍA}

1. Faughnan ME, Mager JJ, Hetts SW, Palda VA, Lang-Robertson K, Buscarini $E$ et al. Second International Guidelines for the Diagnosis and Manegement of Hereditary Hemorrhagic Telangiectasia. Ann Intern Med. 2020 Dec; 173 (12): 989-1001.

2. Faughnan ME, Palda VA, Garcia-Tsao G, Geisthoff UW, McDonald J, Proctor DD et al. International guidelines for the diagnosis and management of hereditary haemorrhagic telangiectasia. J Med Genet. 2011 Feb; 48 (2):73-87.

3. Sholvin C, Bamford K, Sabba C, et al. European Reference Network For Rare Vascular Diseases (VASCERN) Outcome Measures For Hereditary Haemorragic Tellangiectasia (HTT). OrphanetJ Rare Dis. 2018;13:136.

4. Karnezis TT, Davidson TM. Efficacy of intranasal Bevacizumab (Avastin) treatment in patients with hereditary hemorrhagic telangiectasia-associated epistaxis. Laryngoscope. Mar 2011; 121:636.

5. Yaniv E, Preis M, Shevro J, et al. Anti-estrogen therapy for hereditary hemorrhagic telangietasia- a long- term clinical trial.Rhinology. 2011 Jun;49:214

6. Harrison L, Kundra A, Jervis P. The use of thalidomide therapy for refractory epistaxis in hereditary hemorrhagic telangietasia: systematic review. J Larygol Otol. 2018 0ct; 132:866.

7. Albiñana V, Bernabeu-Herrero ME, Zarrabeitia R, et al. Estrogen therapy for hereditary hemorrhagic telangietasia (HTT): Effects of raloxifene on Endoglin and ALK1 expresion in endotelial cells. Thromb Haemost. 2010 Mar; 103:525

8. Boother EJ, Brownlow S, Tighe HC, et al. Cerebral Abscess Associated With Odontogenic Bacteriemias, Hypoxemia, and IronLoading in Inmunocompetent Patients With Right-to-Left Shunting Trough Pumonary Arteriovenous Malformations. Cin Infec Ds. 2017 Aug; 65:595.

9. Post MC, Letteboer TG, Mager JJ, et al. A pulmonary right-to-left shunt in patients with hereditary hemorrhagic telangietasia is associated with an increased prevalence of migraine. Chest. 2005 0ct;128:2485.

10. Chick JFB, Reddy SN, Pyeritz RE, Trerotola SO. A Survey of Pulmonary Arteriovenous Malformation screening, Management,and Follow-Up in Hereditary Hemorrhagic Telangiectasia Centers of Excellence. Cardiovasc Intervent Radiol. $2017 \mathrm{Jul} ; 40: 1003$.

11. Hsu CC, Kwan GN, Evans-Barns H, van Driel ML. Embolisation for pulmonary arteriovenus malformation. Cochrane Database Syst Rev. 2018 Jan;1(1):CD008017.

12. Mohr JP, Parides MK, Stapf C, et al. Medical manegement with or without interventional therapy for unruptured brain arteriovenous malformations (ARUBA): a multicentre non -blinded, randomised trial. Lancet. 2014 Nov; 383:614.

13. European Association for the study of the liver. EASL Clinical Parctice Guidelines: Vascular diseases of the liver. J Hepatol. 2016 Jan; 64:179.

14. Kjeldsen A, Aagaard KS, Torring PM, et al. 20-year follow-up study of Danish HHT patients-survival and causes of death. Orphanet J Rare Dis. 2016 Nov; 11: 157. 